\title{
Information Aggregation: ethical and computational issues
}

\author{
Vincenzo CUTELLO \\ Dept. of Mathematics \\ Uriversity of Cataria \\ Catarizi, Italy
}

\author{
Javier MONTERO \\ Dept. of Statistics ard O.R. \\ Complthterse University \\ Madrid, Spain
}

\begin{abstract}
Is this paper we survey on aggregalion operators and in particular hierarchies of thern. As a case study, we will andyzc the problems of the agercgation of trinth values of luzzy prodicates and the aggregation of individual opinions into a single group opinion, based upon hierarchical itucnsily aggregation rules. Wr will see that hierarchical arnalgamations are supported fruse an athical and rational puint of view. 'Two differenc hicrarchical procedures will br recalled: coverlased hierarchical aggrepations and ordered hietarchical aggregations.

Finally we will see that when we deal with otdered thicrarrhical aggregatiuns of OWA operators. sone interestitg computational problems appiar quite naturally. Sucl probjem admit polynomial time solutious.
\end{abstract}

Key words: Aggregation rules, fuzzy preferences, group decision making

\section{Introduction and preliminaries}

The topir of our distussion is intuitively very situple yet at the basis of maty applications. Cont.rollers, ex] jert and decision making systems, theorem provers, learning algorithens, to mentjon a few, are: all (computer aided) ajplitations in which it is of primary importance to bave methanisms able to analyz the gathered information and produce from it some aggregated value(s) to be (possibly) used in some next evaluation steps.

Comrnon hypothesis to several applications of such kind is that information is passoct to an apgrega. tion operator as an ordered sequence of real numbers, which without. Ioss of gcrerality can be supposed to belong to the unit interval. Formally, an asgregation rule of dimension $n$, will be a mappiug

$$
\phi^{(n)}:[0,1]^{n} \rightarrow[0,1] .
$$

To capture the essential meaning of aggregation, $\phi^{(n)}$ must satisfy at least the following i wo conditions (sice: [15]):

- $\phi^{(n)}(0,0, \ldots, 0)=0, \quad, \phi^{(n)}(1,1, \ldots, 1)=1$ and

- monotonicity, i.e. $\phi^{(n)}\left(a_{1}, a_{2}, \ldots, a_{n}\right) \leq \phi^{(n)}\left(b_{1}, b_{2}, \ldots, b_{n}\right)$ if $a_{i} \leq b_{i}$ for all $i$. 
If we think of $\phi^{(n)}$ as an algroitimn that takes as inputs $n$ numbers and thet it oulputs the aggregatiod value of the 1 uunbers, wi tou obtan aggregatjon rules that ate indrocudent from the number of aggregands by generalizing the abowe definition as follows. Fut

$$
I=\bigcup_{\pi \geq ?}[0,1]^{n}
$$

For every $L \in I$ there exists one and only ont $k \geq 2$ such the $L \in[0.1]^{k}$; such an index $k$ is obviously the "dimension" of $L$, which will weruote by $|\bar{L}|$.

Then $\phi$ on $I$ can be diffued as

$$
\dot{\Phi}(L)=\phi^{(|L|)}(L) \text {. }
$$

For simplicity, we will not sprocify the dimension of the operator whonever it will be clear from the context.

In what. follows we will cuncenterate on two particular applications

1. the aggregation of truth values of fuzzy predicates in a most general and comprehensive way.

2. the aggregation of prefetence intensitims expressed by individual/groups over finite set. of altarma-

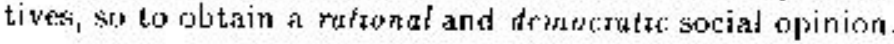

Notics that when we ray thal we want to aggregate gromp opiujons lo obtain a social opinicin we are basically saying that we want lo aggregate values which are themsetves an aggrregation of valtes. Therefore; a further generalizatiou of the above definition of aggregation rules is oblained by introducing the notion of hierarchical aggregations, that is to say aggragations of chunks of information which in t.turn represent iLggregaled informations.

In general, hierarchical agorgation procedures for individual preferences are defired by means of a basic classification of tle individas. The set of individus is clivided into groups, in such a way that each indivitual is present in at least one of these groups. An immediate cxample is provided by nationa] Parliaments. Fach of the representative of the Parliament has been elected by a particular group of people and therefore he/sh: represents tha' aggegated opinion th such people. When thi Parliatsent express ils opinion then what we hase is an hierarchical aggregation of the pudple opinions. Since volers are generally divided irto elertoral districts, we have a fixed "cover" of the set of indivisluals.

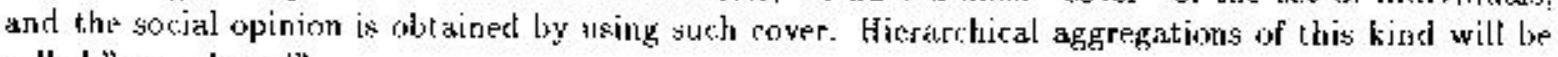
called "cover-based".

Altermatively: basic classilicatson cat be tuade on the basis of a naturat ordering ou all possible intersity values, and then wo carl talk about "ordered" hierarchical aguregation rules. T'his setond type of hierarchical aggregations are obviously more naturat when dealing with fuzzy predicateas trutith agrtegations.

\section{Truth values aggregation}

One of the main issues in Fuzzy Logic is the choice of operators to generalize the talasical logic operators ard, or. Many propusal have been mack and the most gincral formalizations are represented by $T$. uorms, T-conorms and OWA operators (see $[23,24]$ ).

A T-norm is a map $T:[0,1] \times[0],] \rightarrow[0,1]$ such that

(T1) $T(a, b)=T(b, a)$

(T2) $T(a, T(b, c))=T(T(a, b), c)$ 
(T3) $T(a, b) \geq T(c, d)$ if $a \geq c$ anc $b \geq d$

(T4) $T(a, 1)=a$

A T-conorm is a map $s:[0,1] \times[0,1] \rightarrow[0,1]$ such that

(S1) $S(a, b)=S(b, a)$

(S2) $s(a, S(b, c))=S(S(a, b), r)$

(S3) $s(a, b) \geq s(c, d)$ if $a \geq c$ and $b \geq d$

(SA) $S(n, 0)=a$

T-norms and T-cunorms represent atggregaticun uperalors that generalize the notion of conjunclion and disjunclion of classical logic. Thr min operator is the maximal T-norm and the max operator is the minimal $T$-conorm, in the sense that for all $a, b$ ws have that $T(a, b) \leq \min \{a, b\}$ and $S(a, b\} \geq \max \{a, b\}$ hold for any T-borm $T$ and any 'T ronorm $S$ (sce: [15]).

Ordered Wetghted A teraging ( $O W A$ ) uperators fill the gap betwecn trin and max, in such a way that.

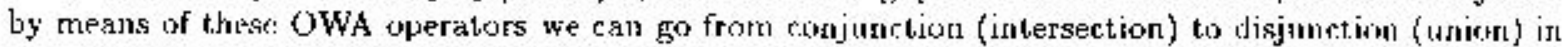
a continuous way. OWN operators witre initially introduced by Yager in [24]: and they have been used and applied to matay fields, such as Neural ivetworks, Database systems, Learming systmis and Fuzzy Logic ('ontrollets (sce [25] for a comprehensive revirw on the subject). In order to gett the aggregated values, OWh operators make nis: of the relative orter within intensily values.

Formelly: an OWA operator of dimension no is at aggregation operator do that lids ans absoc iated lest of werglts $W=\left[t_{t}, \ldots, t_{n}\right]$ such $t$ tat

1. $u_{i} \in[0,1]$ for all $1 \leq i \leq t 2$

2. $\sum_{i=1}^{n} w_{i}=1$

3. for any $\left.L=\left[a_{1}, a_{1}, \ldots, a_{n_{1}}\right] \in \mid t,\right]^{\pi}$

$$
\phi(L)=\sum_{i=1}^{n} t w_{i} b_{2} .
$$

where $b_{1} \geq \cdots \geq b_{n}$ is the sequence obtained whon we sort in non decreasing order the inputs $a_{1}, a_{2}, \ldots, a_{n}$.

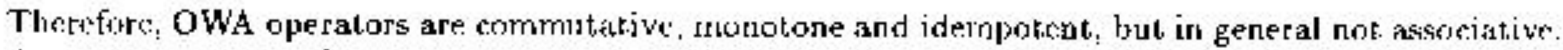
As a corsequence, the semantice problents of using the sirne OWA operator on imputs of diffircht. dimensions, i.e. the problem of defining the OWA uperator $\phi: I \rightarrow[0,1]$ given the OWA operators $i^{(n)}$ is cuite challenging. An answer to surh a problem has been given in [10] where it is introducted the notion of recursive families of OWA operators. For the tirne being, we will jogncre suct a problem and we will only deal with a particular type of hierarchical aggregation which we will cal] ordered hierarchitat aggregation and that will allow us to deal in a very natural way with owh operators.

\section{Aggregation of preference intensities}

The classical Arrow's paradox in group drecision making (cfr. [1]) when translated into a fuzzy context. (see $[2,13,14,17,20]$ ), can be avoided in several ways, according to axiomatics which are simular to those proposed in the crisp context. As we mentioned above it. is very common to obtain aggregated 
preferences of large grolujs of pcople by means of rules which allow the successive aggregation of drgrees of preferences. The set of individuals is divided into smballer subsets of inclividuals -not. nocessiarely disjoint- and the global aggrogation will be the aggregation of all partial atgregations within each one of these subsets of individuals. We toliow the mode] proposed in [38. I0] and silsse ipentely characterized in [5]: and the formalization given in [7].

At the basis of sucti a model are not alsolutely irrational (in the sense of $[13,190]$ ) complete [uzzy preference relations. In particular, it is essumed that each individual is able to cxpress her/his opunion about. any possible set of alteruatives through sime coutulebe fuzzy binary preference relation, as formalized below.

Lat $\mu: X \times X-[0,1]$ be a fuzzy preference relation uver al arbutary finde set of altematives $X . \mu(x, y)$ represents the clegree to which the relation $x$ not worse thin $y$ holds. The corrijulctarems hypothesys is ex]ressicd by

$$
\mu(x, y)+\mu(y, x) \geq 1 \forall x: y \in X
$$

Following [4], cormpleteness is required in order to assure that all indivirluals cousidn the sel, of adternatives on which they arr: expressing their opinions, frasible and comprebersive.

The valuos

$$
\begin{aligned}
\mu_{S}(x, y) & -\mu(x, y)+\mu(y, x)-1 \\
\mu_{B}(x, y) & =\mu(x, y)-\mu_{T}(x, y) \\
\mu_{W}(x, y) & =\mu(y, x)-\mu_{S}(x, y)
\end{aligned}
$$

tall be understood. respectively: as the degree to which the two alternatives are indifferent $(x f y)$, the

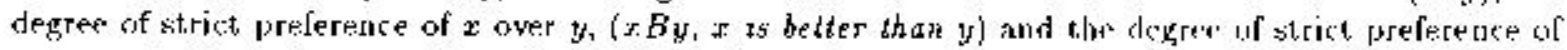
$y$ over $x$ ( $x$ W $y, x$ is morse than $y)$. We clearly have tifat.

$$
\mu_{B}(x, y)+\mu r(x, y)+\mu w(x, t)=k \forall \cdot y .
$$

We want to define ration iblity as a fuzzy property. Wi: thell consider cycles of prefesenese over chatins: $C_{i}=\left(x_{1} \cdots x_{2}-\cdots-x_{k}-x_{1}\right)$ of $k$ distint alternaljes, defined as

$$
x_{1} F_{1} x_{2} F_{2} \cdots r_{k} P_{k} x_{1}
$$

where $F_{h} \in\{W, f, B\}$ for all $A-1,2, \ldots, k$. A cycle $x_{1} P_{1} x_{2} P_{2} \cdots x_{k} P_{k} s_{1}$ is irmitonat if cither

- $P_{h} \in\{B, h\}$ for all $h=1,2, \ldots, k$ and $B \in\left\{P_{h}: h=1,2, \ldots k\right\}:$ or

- $P_{h} \in\{W, 1\}$ for all $h=1,2, \ldots, k$ and $W \in\left\{P_{h}: h=1,2, \ldots, k\right\}$.

We say that. a cycle is rational if it is not irrational. Then, given any fuzzy proference $\mu$ over a fixed satt of alternatives and a chain of allernatives, we can look for all possible rational cycles of preftrench, weigh them in some way abd assign to the chain a dogree of rationality (see $[5,18]$ ). Spenifically: this: is done as follows. (iven a a cycle $C \equiv x_{1} P_{3} \cdots x_{t} P_{k} x_{1}$ where $P_{h} \in\left\{B_{1} I . W\right\}$ for all $h_{h}=1,2, \ldots, k, a$ quite natura] weight. associaled to $C$ and denoted by $\Delta(C)$ is

$$
\Delta(C)=\Pi_{h=1}^{k} \mu_{P_{4}}\left(x_{b}, x_{h+1}\right)
$$

where $x_{t+1}=x_{1}$ for convenience.

Therefore, given a chain $C=\left(x_{1}-x_{2}-\cdots x_{p}-x_{1}\right)$ a degree of rationality associated to $G$ and denoted by $A_{k}(C)$ can be defined as

$$
A_{s}\left(C^{r}\right)=\sum_{\text {C:E rat.cycles }} \Delta\left(C^{\prime}\right)
$$


As proven in [5.18], $A_{\mu}(G)$ verifies

$$
1-A_{\mu}(C)=\prod_{h=:}^{k} \mu\left(x_{h}, x_{h+1}\right)+\Pi_{h=1}^{k} \mu\left(x_{h+1}, x_{h}\right)-2 \Pi_{h=1}^{k} \mu_{j}\left(x_{h: x_{h+1}}\right) .
$$

In view of (3.4), once a finite set do alternatives $X$ has becn fixed, ralionality can lee defined as a fuzzy Hroplurty $A: P(x)-[0,1]$ with

$$
A(\alpha)=\min _{G} A_{\mu}(C)
$$

alt where $T(X)$ is the set of all complete fuzzy preferences. Needless to say, the aloove is just a particular rationality measure, which may or may not stem "rational". A formal characterizatijon of rationa]lty measures: was given in [8], following the approash described in [6]. The alosye: dtower ibed rationality me:tisure as well as the thost commonly found in litarat.ure, are particular instance of anch general rlefiutitorn. It would then be desirable to extertht the results that we will describe below to "gecresic" fuzzy raticutality measures.

Once: it group of $n \geq 2$ indivituals is fixed, we should be alde to aggregate their opinions albout. any sel of alternativisy in a coherent way. Therefore, in [5] were delined aggregation operations that

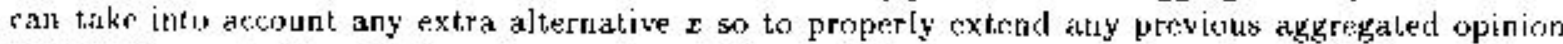
relativi to a collection of altertatives not containing 2 . The key preperties are the standard conditions

(IIA) Independence of Irrelevant Altematints; each aggregated preference relation $\mu(x, y)$ drspectis solely on the values $\mu^{i}(x, y)$, i.e. on the individual preferemes intensitices of $x$ over $y$

(UD) lurstracted bomain: the aggregation rule is defincd aver all possible profiles of fuzzy preferences.

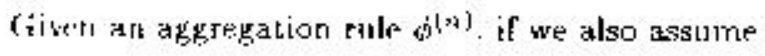

(N) Sheritrifty: given any permutatijon of the set of alternatives $\pi$ : if $\nu^{i}(x, y)=\mu^{i}(\pi(x), \pi(y))$ for all $i=1,2, \ldots, 1$ and any pair of al ternatives $x, y$, thent

$$
\phi^{(n)}\left(\nu^{1}(x, y\}, \cdots, \nu^{n}(x, y)\right)=\phi^{(r)}\left(\mu^{1}(x, y), \cdots, \mu^{n}(x, y)\right\}
$$

It is clear then that. the sarne aggregation $\phi^{(n)}$ will be associated to any pair of altetruativus attd therefore tach possible aggregation procedure is characterized by one of these aggregation rules.

For the time being. we will suppose that conditions IIA, UD, $N$ hold.

(iiven $n$ individuals expressing theic opinion on the set of alternatives $X$ and $\phi^{(n)}$, the aggregated

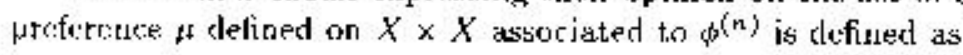

$$
\mu(x, y)=\psi^{(n)}\left(\mu^{1}(x, y), \cdots, t^{n}(x, y)\right) \forall x, y \in X .
$$

Standart ethatiat conditions may also be imposed on the intensity aggregation rules, among them:

(PR.) Positive: Responsiveners:

$$
\phi^{(n)}\left(a_{1}, a_{2}, \ldots, a_{x_{1}}\right)>\phi^{(n)}\left(b_{1}, b_{2}, \ldots, b_{n}\right)
$$

if $a_{1} \geq b_{i}$ for all $i=1,2, \ldots, n$ and there exists $I \leq j \leq n$ such that $a_{j}>b_{j}$.

(A) Anonimity: given any permutation $x:\{1, \ldots, n\} \rightarrow\{1, \ldots, n\}$, we have

$$
\phi^{(n)}\left(a_{1}, a_{2}, \ldots, a_{n}\right)=\phi^{(n)}\left(a_{\pi(1)}, \ldots, a_{\pi(n)}\right) .
$$


(U) Viratrimtty: if $a_{i}=a$ for all $i:=1,2 \ldots, n$, then

$$
\phi^{(+)}\left(a_{1}, a_{3}, \ldots, a_{41}\right)=a
$$

(CS) Cttazen sovereign: for any given $a \in[0,1]$ there exists a profile $\left(t_{1}, a_{2}, \ldots, a_{n}\right) \in[0,1]^{n}$ such that $\phi^{(n)}\left(a_{1}, \alpha_{2}, \ldots, a_{3}\right)=a$.

(ND) Non Dickatorsh:p: there is no individual $i$ such that

$$
\phi^{(n)}\left(a_{1}, u_{z_{1}} \ldots, a_{3_{2}}\right)=a_{i}
$$

for any $\left(a_{1}, \ldots, a_{i-1}, a_{i+1}, \ldots, a_{n}\right) \in[0,1]^{n-1}$.

Wo will say that an intensity aggregation rule is comptete if and only if the assorejated aggregated fuzzy prefiercoce is complete for any profile of coctulete individual preferences.

A characterization of complete aggregations rules is given by the following letuma proven in [5]

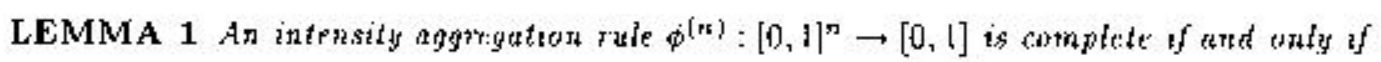

$$
\phi^{(n)}\left(a_{1} \ldots, a_{n}\right)+\phi^{(n)}\left(b_{1}, \ldots, b_{n}\right) \geq 1
$$

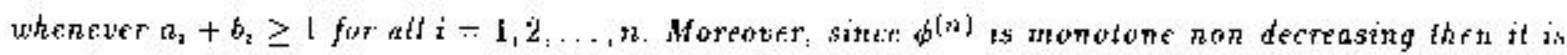
complfite if ind only of

$$
\phi^{(n)}\left(a_{1}, \ldots,\left(a_{n}\right)+\phi^{(n)}\left(1-\alpha_{1}, \ldots, 1-a_{n}\right) \geq 1\right.
$$

for alt $\left(a_{1} \ldots, \ldots, a_{n}\right) \in[0.1]^{n}$.

Tlu aldove given fuzzy property of tatimality is extended to aggregation rules iu twe following way.

DEFINITION 1 Gizien $n$ zrdividuals, an eggregation tute $\phi^{(n)} ;[0,1]^{n}-[0,1]$ is non absolutely irrational (WAI), or simply non irrational, if for any arbatrary finite set of altematimes $X$, the assocrated aygregated preference $\mu: X \times X \rightarrow[0,1]$ is complete and non absofutely irrutsonal. i.e. $A(t t)>0$, whenever all individtats are complete and non absolittely irrutonal themselves, i.e. $A\left(r^{i}\right)>0$ fur uth $i=1,2, \ldots$, ri with $\mu^{i}: X \times X-[0,1]$ for all $i$.

It is thear that in this way both indivislud and social opinions arc reguire:cl to belong to the set of Non-Absolutely Irraticinal (NAI) complete fuzzy prufereuce relations. Therefore, wo ate in fart. Therlifying the Uncestricted Domain condition.

The main result proven in [5] is the following.

THEOREM 1 Let $\phi:[0,1]^{n} \rightarrow[0,1]$ be a complete intensity afgregation rute verdying condition $A$. Thets is is NAI if and only if thr following conditions hold:

(1) If $_{a_{i}}+b_{i}>$ k for all $i=1,2, \ldots, n$, then $\phi\left(a_{1}, \ldots, a_{n}\right)+\phi\left(b_{1}, \ldots, b_{n}\right)>1$,

(ii) $\phi\left(a_{1}, \ldots, a_{n}\right)=1$ sisphes $a_{1}=1$ for all $i=1,2, \ldots, n$.

Morwover, from the proof of theorem $t$ it can be concluded thal in order for a compleste intensity aggragation rule to be NAI, conditions (i) and (ii) are sufficient.

I'wo immediate corollaries of theorem $f$ atc. 


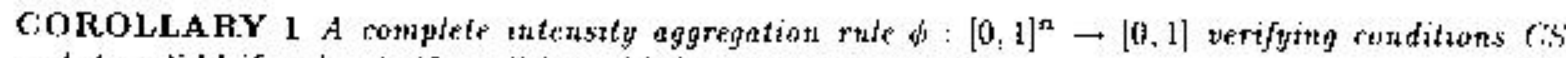

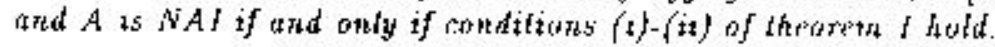

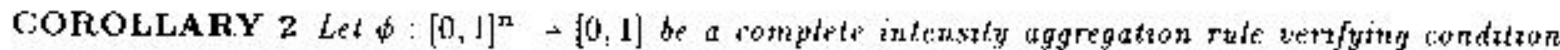
FR. Then $\phi$ is NAI.

Example 1 By applying Coroltary 2 we can easily prove 1, tat, the following intensity agoregation rule (see [ts]. pg. 6(b) is $\mathrm{NAI}$ :

- Weighted Generalized Mrat: given $w_{1}, \ldots, w_{n}$, pensitive real numbers and $r \geq 1$, theu

$$
W G M\left(\alpha_{1}, \ldots, a_{,}\right)-\left(\sum_{i=1}^{n} \frac{w_{i}\left(a_{i}\right)^{r}}{\sum_{j=1}^{n} w_{j}}\right)^{\frac{1}{r}}
$$

where the assurnption $r \geq 1$ thas been made in orider tro assure completeness.

\section{Cover-based hierarchical aggregation rules}

('over-based hierarchical aggregation rules appear in practice wiben the whole set of individuals is previously tivided into groups (nol necessately disjoint), it such a way thit. the fumilganalion is obtainet by rreans of those subsets of individuals. Sorretimes the srocitty urder study is naturally

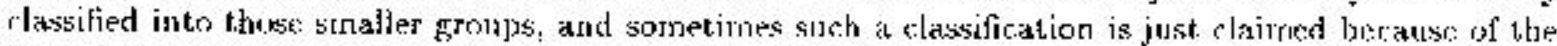
large dimension of the group. Hince, final aggregation will be oblained as an amalgamatiou of all those partial aggregations.

Let us now introcluce sone notátions which will bo nsofuld for our [uture discussions.

By $\left[i_{1}, i_{1}, \ldots, i_{n}\right]$ we will denote the ordred list whose fiest cloment is $i_{1}$, second element is $i_{2}$ and so on. [ will denote the emjty list and given a list. $L$. $|L|$ will denote the length dof the list Moreover, let. the the rlassical Jist composition operator. Finally, given a list $L$ we define the operator * thict

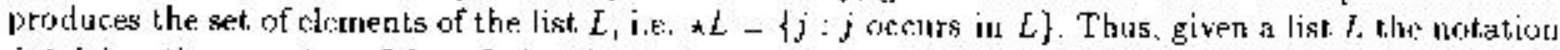
$j \in t$. has the meaning of $j \in * L .|* L|$ will deturte the cardinality of the $k$ r.t $* L$ and since sets have no ropelion of elements il is cleat that $|* L| \leq|S|$ for any list $L$.

So, if

$$
L_{1}=\{1,2,3] \quad L_{2}=[3,2,4,3\} \text {. }
$$

We have,

$$
\star L_{1}=\{1,2,3\}, * L_{2}=\{3,2,4\} .
$$

Givecu a list $I$ and $m$ lists $I_{3}, \ldots, I_{m}$ we sety that the list $T=\left[I_{1}, \ldots, I_{m a}\right]$ is a cover of $I$ if the following conditions are verıfted:

- Is $\neq \emptyset$ for all $k=1,2, \ldots, \mathrm{r} t$ :

- for all $k=1,2, \ldots, m$, we have $|\star f|=|I|$ i.e. all the elements in $I_{k}$ are different :

$* \star I=\bigcup_{t=1}^{m} \star I_{k}$.

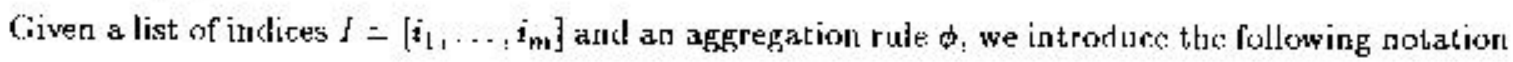

$$
\phi\left(a_{h} \mid h \in S\right) \equiv \phi\left(a_{1}, \ldots, a_{i_{m}}\right) \text {. }
$$

Then we can define the concept of cower-based hierarchical aggregation. 
DEFINITION 2 Let $I$ de is finfe last of indices and let $\left[f_{\mathrm{t}}, \ldots, f_{\tau_{\mathrm{n}}}\right]$ be a fixed cover of $f$. Lt: the $=|I|$ and $c_{k}-\left|f_{k}\right|$ for at/ $k-1.2$. in A cover based bierarchical aggregation $\phi$ ts characterazed by a collection $p_{0}, \phi_{1}, \phi_{2} \ldots, \dot{\phi}_{c_{n}}$ of aggregation rates with $c_{0} \geq 2$ ard with $m_{k}>1$ for somp $1 \leq k \leq c_{0}$ such that $\phi_{k}:[0.1]^{r+} \rightarrow[0.1]$ for all $k=0,1,2, \ldots, r_{0}$, in stech a tway that the compositrout

$$
\omega=\phi_{0}\left(\omega_{1}\left(\phi_{2}, \ldots, \phi_{c_{D}}\right):[0,1]^{m} \rightarrow[0,1]\right.
$$

is definter is

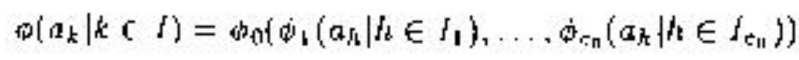

To clarify anfinition 2 corsides the following example. Irt $f=\{1,2,3,4]$ and for $c_{0}=3$ consider the cover $\left[f_{1}, f_{2}, t_{3}\right]$ with $f_{1}=[1,2], f_{2}-[2,3,1], t_{3}=[4,1,3]$. So given any inpul $\left(a_{1}: a_{2}, a_{3}, a_{4}\right)$ we have

$$
\phi\left(a_{1}, a_{2} \cdot a_{2} \cdot a_{4}\right)=\phi_{1}\left(\phi_{1}\left(a_{1}: \alpha_{3}\right), \dot{\phi}_{2}\left(a_{2}, a_{3}, a_{1}\right), \phi_{3}\left(a_{A}, a_{1}, a_{3}\right)\right) .
$$

Assuming an a priori fixed cover $\left[t_{1}, \ldots, t_{r .0}\right]$ of $f$ e cach hicrarchical aggregation is therefore characterized lyy the composition $\omega_{1}\left(\omega_{1}, \omega_{2}, \ldots, \phi_{c_{\mathrm{p}}}\right)$.

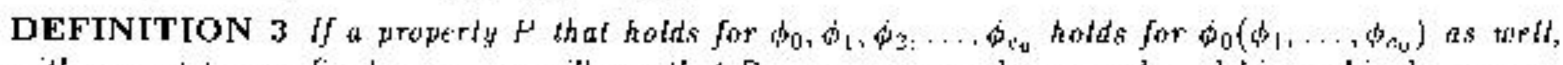
with respect to any fired corer, tws rild say that $P$ propagates under cover-based hierarchiral aggregations.

Ore important property that propagales under cover-based hierarchical aggregation is stabelaty as defiuted and analyzed in [7] $]$.

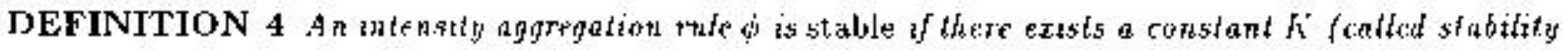
constant) such that fur adt $(>0$ and for all $i-1, \ldots$ m.

$$
\left|\phi\left(a_{1} \ldots, a_{1}-1, a_{1}^{\prime}, n_{j}+1, \ldots, a_{m}\right)-\phi\left(a_{1}, \ldots, a_{m}\right)\right| \leq K \epsilon
$$

for adt $a_{1}, \ldots a_{m}$ asd for $u_{1}^{\prime}-a_{t} \mid<x$.

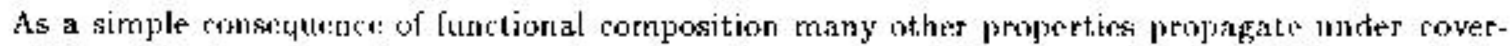
based hierarchical aggregations. amoty them completeness, positive resiponsiveness (PR), unanimity (U) and couditions (i) and (ii) of theorem L. Bring NAI also propagates, as show in the frollowing itiensent.

THEOIREM 2 if $\phi_{\mathrm{n}}, \phi_{1}, \phi_{2} \ldots, \phi_{\mathrm{c}_{0}}$ are NAI aggregation rutes then $\phi \equiv \phi_{0}\left(\phi_{1}, \phi_{2}, \ldots \phi_{r_{n}}\right)$ as also NAI, i.t. rationaldy propagates under cover-based hetruxhach aggregations.

Proof. Let. $X$ be a set of alternatives and let $\mu t, \ldots, t I^{7}$ be: $n$ NAI individuals. Let us denote by $\nu$ the aggregation function associated to $\varphi^{9}$ atsol lyy $\nu_{k}$ lhe aggregation function associated to $\phi_{k}$ for all $k=0,1.2, \ldots, c_{0}$. Since all the individuals $\mu^{\prime}, \ldots, \mu^{r}$ are $N A I$ so are $\nu_{1}, \ldots, \nu_{c_{u}}$. On the other hand, since $\varphi_{n}$ is NAl and in view of definition l, we haw: that its aggregation function $v_{0}$ defined as

$$
\nu_{0}(x, y)=\phi_{0}\left(\nu_{1}(x, y), \ldots, v_{c_{0}}(x, y)\right)
$$

is NAI. This:refore, since

we tave that $\phi$ is VAl.

$$
\nu(x, y)=\nu(x, y)
$$

It is easy to observe that anonimity (A) and citizen sovereign (CS) do not in genoral juppagate under cover-luased tiverartical aggregations. However, it tall be proved they propagate in specific bul. irmportant cases (see [7] for details). 


\section{OWA Operators and Ordered Hierarchies}

We will now introluce ordered herarchical aggrogations. Such hierarchical aggregations are related very naturally to the Ordered Weryhted Arenging (OWA) operators.

As previously cotmmented, for any $O W h$ operator $\phi$ we have

$$
\underset{1}{\min }\left(a_{1}, \ldots, a_{n}\right) \leq \phi\left(n_{1}, \ldots, a_{n}\right) \leq \max _{i}\left(a_{1}, \ldots, a_{n}\right)
$$

Two significative miasures are associaled with OWA operators (soe Yager [24]). (tiven $\phi$ of dimen-

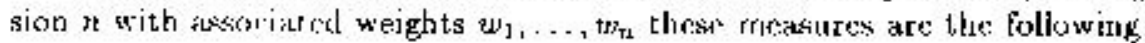

(u1) degree of orness. i.c. flew clese an Owis operator in to the max operator. It is defined as

$$
\operatorname{orntss}(\phi)=\frac{1}{n-1} \sum_{i=1}^{n}(n-i) w_{i} .
$$

Dual to the modisure of ordess as the measure of and aress defined as

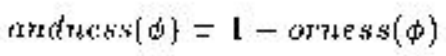

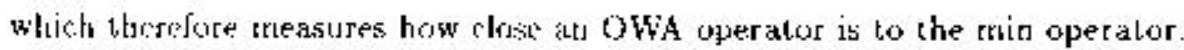

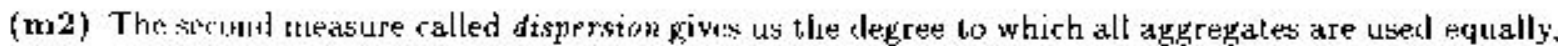
i.e. the degres to which ar OWA operator is close to the simple average operator. The dispersitun rucasure is clefined as

$$
\operatorname{Disp}(\phi)=-\sum_{i=1}^{n} w_{i} \ln w_{\mathbf{i}}
$$

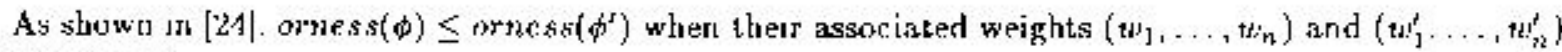
yerify that

$$
\sum_{j=1}^{t} w, \leq \sum_{j=1}^{i} w_{j}^{j} \forall i=1, \ldots, n
$$

This property gives in fact the innitive idca of when an OWA operator must be more an "or" than other OWA operator An importanl class of OWA operator is the class of buegancy measures definrd as foltows (sec $[24]$ ).

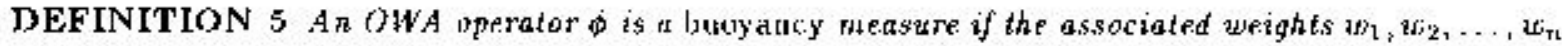
verafy the condeloon $t_{i} \geq 1 w_{j}$ for alt $i \leq j$.

Buoyancy meatures verify the property of bring orlike meusures, i.e. if $\phi$ is a buoyancy measure thex orress( $\phi) \geq \frac{1}{2}$. Buoyancy measures verify as well an important property for gur future ctiscussions (see $[11\}$ \}

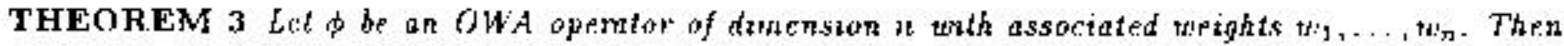
$\phi$ is rotnplete. if and ordy if for all integer $k \leq \frac{\pi}{2}$ we have

$$
\sum_{i=1}^{k} t i_{3} \geq \sum_{i=1}^{k} w_{n-i+1}
$$


Therefore. since tuuryarry trutasures verify condition (5.8) they are complete.

A characterization of OWA operalors in terms of "fuzzy ratiouslity" is given by the following theworem.

THEOREM 4 Let $\phi$ be a complete OWA optrutor with assoctated wetghts wh . ., wh. Tht: th $\phi$ is NAI if at?d und of $w_{n}>0$.

Provf. We remark that (IWA operators verify the pre-conditions of theorem 1 . We will nuw show that an completer OWA optrat or verilies condition (i) of theorem $\mathbf{I}$.

Suppatse then that $a_{2}+b_{\mathrm{t}}>1$ for all $i=1,2, \ldots$, r. Therefore $a_{[n]}>0$ and $b_{[n]}>0$ froth whit.h we also bave that there exists i $>0$ sucli that for all $i=1,2, \ldots, n$

$$
\begin{aligned}
a_{1}+b_{1}-r & \geq 1 \\
b_{i}-r & \geq 0
\end{aligned}
$$

Wo thin have

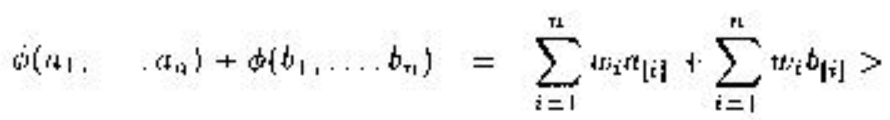

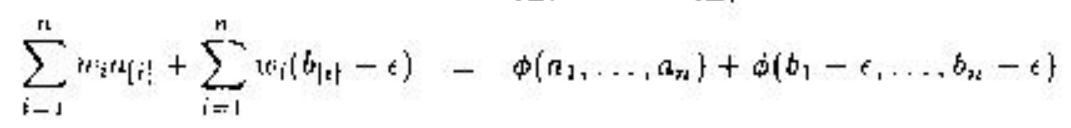

and the Jatter is not smiller t.tian I for the completeness hypothesys.

In ordes to prove our theorecr it. is enough to prove that $w_{n}>0$ if and only if condition (ii)

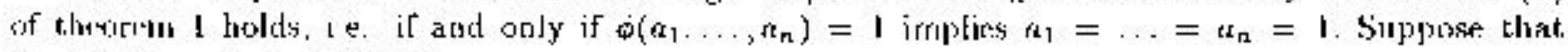
$a_{1} \geq a_{2} \geq \ldots \geq a_{\mathrm{m}}$. Whe have

$$
q\left(\alpha_{1} \ldots \ldots \pi_{r}\right)=\sum_{i=1}^{r_{1}} w w_{i} \iota_{i}=1 \leftrightarrow w_{i}=0 \forall\left(t_{i}<\mathbf{I} .\right.
$$

In thera we have-

- if $\phi\left(a_{1}, \ldots, a_{n}\right)-1$ and $a_{n}<1$ then $w_{n}=0$;

- if $w_{n}=0$ then $\phi\left(1 \ldots, 1, a_{n}\right)=1$ for all $a_{n} \in[0,1]$

and thts: theurem is provest.

As a simple ronsecpluence: wr: have

CUROLLARY 3 A btophney menstare is MAl if and onty if all its associated weights are non null.

\subsection{Ordered hierarchies of OWA operators}

It can easily be olsatrved thith aver-based lierarchical aggregations of OWA operators do not in general produre OWA rperators since cover-based hierarchical aggregations are characterized by a lixed cover of inclividuats: independently of their opinions. Wo will now give a characterization of hierarchical aggregations of $O W A$ operatirs that produce OWA operators.

let. $\phi_{0,} \phi_{1}, \ldots, \phi_{\mathrm{c}}$ be $c+1$ OWA operators such that. 
- \$ro has dimension r;

- $\phi_{2}$ has dimension $h_{i}$ for any $i=1,2, \ldots$, .

- $\sum_{i=1}^{n} h_{i}=n$

Let $w_{0,3}, \ldots, w_{0,5}$ be the weights assuciated to $\phi_{0,}$ and for all $i=1, \ldots c$ let $u_{2}, 1, \ldots, w_{1, h}$, be the weights associated to $\phi_{\mathrm{i}}$

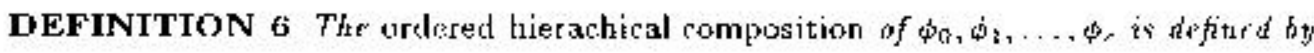

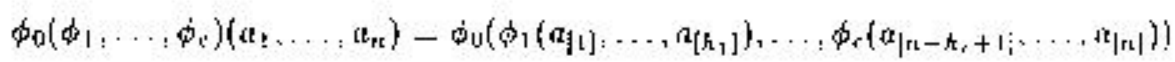

for aft $n-u p i t s\left(a_{1}, \ldots, a_{n}\right)$.

DEFINITION 7 If a property $P$ that hutds for $\phi_{0}, \phi_{\mathrm{f}}, \phi_{2}, \ldots$, $\phi_{\mathrm{c}}$ holds for the ordered hae rarhical ag-

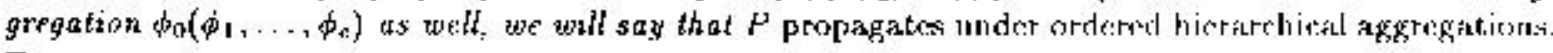

The result we were looking for follows.

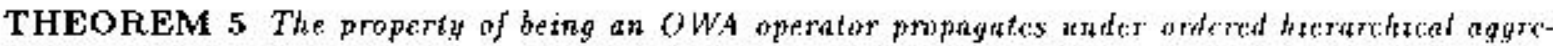
sations.

Proof. Given any $n-m p l e a_{1} \ldots, a_{n}$ suth that, $a_{1} \geq a_{2} \geq \ldots \geq a_{n}$, because of property 3 .ti for the OWA roperalors; we have

$$
\phi_{1}\left(a_{1}, \ldots, a_{h_{1}}\right) \geq \cdots \geq \phi_{n}\left(a_{t_{2}-\hbar_{n}+1}, \ldots, a_{n}\right)
$$

Let $\alpha_{j}=\sum_{i=1}^{j} h_{i}$ for any $j-1, z_{i} \ldots, c$

We have

$$
\begin{aligned}
& \phi_{u}\left(\phi_{1}, \ldots, \phi_{n}\right)\left(a_{1}, \ldots, a_{n}\right)=\phi_{0}\left(\sum_{i=1}^{h_{1}} w_{1, i} \alpha_{i}, \ldots, \sum_{i-a_{c-1}+1}^{12} u r_{r, i-r_{r-1}} a_{1}\right\}-
\end{aligned}
$$

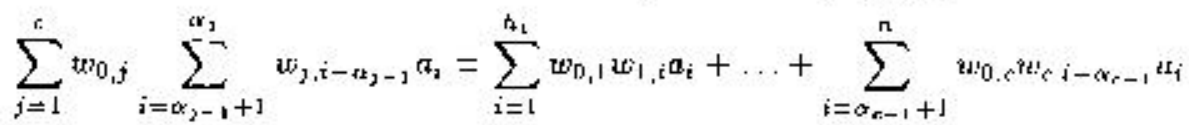

Finally, since.

$$
\sum_{i=1}^{h_{1}} w_{0,1} w_{1, i}+\ldots+\sum_{i=\alpha_{s-1+1}}^{n} w_{0, r}\left(t_{c, i}-\alpha_{s-1}=1\right.
$$

we catu clairu that the ordiered hierachical aggregation produces an OWA oprerator

Thus, the above defined ordered hierarchical aggregations ars such that the property of being an OWh operator propagates. However, as it is easy to see, completeness does not propagate in guneral for ordered hierarchical aggregations. Moreover -in view of theoresn 5- Monotonicity, Idempotency, (Commutativity, Stability and $N$ on Alssolute Irrationalily (whenever completeness propagates) jropagate under ordered hierarchical aggregations of OWA operatiots. 


\subsection{Orness and Dispersion}

(Given a fixed ordered hierarchical aggregation $d \equiv \phi_{0}\left(\phi_{1}, \ldots, \phi_{A}\right)$ bastal npon $r+1$ owh operators, the degree of orness is given by

$$
\operatorname{orness}(\phi)=\phi\left(\frac{n-1}{n-1}, \frac{n-2}{n-1}, \ldots, \frac{1}{n-1}, \theta\right)=\phi_{0}\left(z_{1}, \ldots, z_{1}, \ldots, z_{n}\right)
$$

where

$$
\begin{aligned}
& z_{i}-\phi_{i}\left(\frac{n-\left(\sum_{-j=1}^{i-1} h_{j}+1\right)}{n-1}, \ldots \frac{n-\sum_{j=1}^{n} h_{j}}{n-1}\right)=\sum_{m=i}^{n_{0}}-\frac{n\left(\sum_{j=1}^{j-1} h_{j}+m\right)}{n-1} m_{2, m}=
\end{aligned}
$$

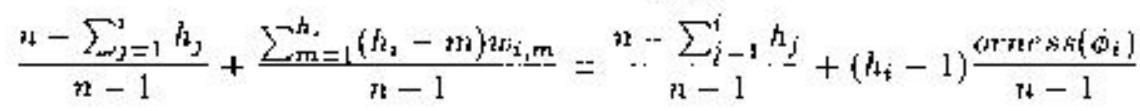

for all $i=1, \ldots, c$, with $h_{i}$ the dimension of cath $\phi_{i}$ atd $\left(w_{i, 1} \ldots, t_{i, h_{2}}\right)$ its associated weights. Hence,

$$
\operatorname{orness}(\phi)=\sum_{i=1}^{c} \frac{\left(h_{\mathrm{t}}-1\right) \operatorname{orness}\left(\phi_{\mathrm{l}}\right)+n-\sum_{s=1}^{t} h_{j}}{n-1} w_{0 . i}
$$

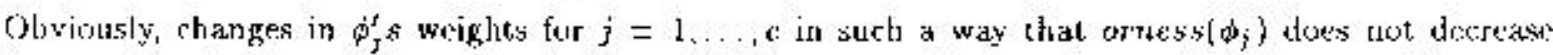
fror any $j=1, \ldots, c_{0}$ will never make ortess $(\phi)$ decreatit. Hohtevor. increasing ornfss $\left(\phi_{b}\right)$ dow not. necessarely increase ormt:ss( $\phi$ ) als show by the following example

Fxample 2 Lrd, $\dot{\phi}_{0}, \phi_{0}^{\prime}$ be two OWA operators of dimension r. stech that their associated weights are, respectively, $w_{0,2}=1, w_{0, i}=0$ for all $i \neq 2$ and $w_{0,3}^{\prime}-w_{0.3}^{\prime}-1 / 2_{1} w_{0,2}^{\prime}=0$ for all $i \neq 1,3$. Tluen,

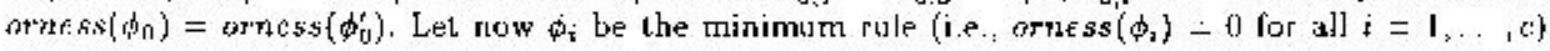

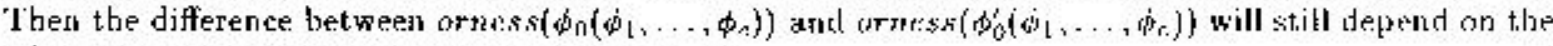
relative sizes $h_{2}$ and $h_{3}$ of $O W A$ oprators $\phi_{2,} \phi_{3}$

'Ithe dispersion of the hierarchical aggregation cat be computed as follows.

$$
\begin{aligned}
& \left.\operatorname{Disp}(d)=-\sum_{j=1}^{c} \sum_{i=1}^{h_{j}} w_{0, j} w_{j, i} \ln \mid w_{0, j} w_{j, \mathrm{c}}\right]
\end{aligned}
$$

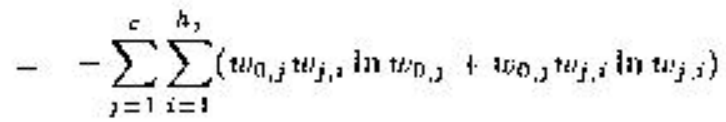

$$
\begin{aligned}
& =-\sum_{j=1}^{c} w_{0, j} \ln w_{0, j}-\sum_{j=1}^{c} w_{0, j} D_{i s} p\left(\phi_{j}\right) \\
& =\operatorname{Disp}\left(\phi_{0}\right)+\sum_{j=1}^{c} w_{0,3} \operatorname{Hisp}\left(\phi_{j}\right)
\end{aligned}
$$

Thurefors: the dispersion of the hiecarchical aggregations defpends directily upon the tisisersions of Lhe given OWh operators.

In botll cayes it is however clear that once the operators $\phi_{0}$ and $\phi_{1}, \ldots, \phi_{c}$ are fixcil then the orness and lispersion values of the hierarchical aggregation depend upon the particular ordering of the $r$ owA operators $\phi_{l}, \ldots, \phi_{n}$.

It is then natural to ask the following questions: 
(1) How can the puzkly find an ordering of throse c OWA aggregated operators which suaximizes [respr. minimizes] the dispersion vatue of the hierarchical aggregation?

(2) Hlow can one antckly find an ordering of those c OWA aggregatexl operators which maximizes [resid. thinimizes] the orness value of th: hicerarchical aggregation?

In the rext, section we will provide comprlete solutions for them followng the results in $[5,12]$.

\section{Maximizing and minimizing dispersion and orness}

Let. $d_{0}$ lse an OWA operator of dimension $c$ and let. $\Phi=\left\{\phi_{i}: 1 \leq i \_c\right\}$ be a given set of olva

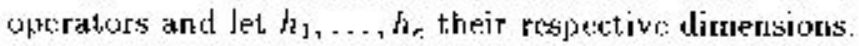

\subsection{Dispersion}

We start by providing polytumial algorithrns to maximize [resp. minimize] the dispersion of the hierarehical agyegration.

Let $\pi$ be a permutation of the indices $\{1,2, \ldots, c\}$ such that

$$
i \leq j \text { if and only if } t t_{0, \pi(i)} \geq t_{i(j, r 1 j)}
$$

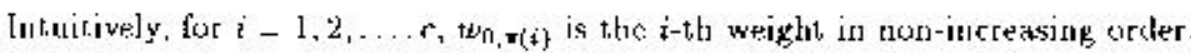

bet $\phi_{1}, \ldots, \phi$. lic it given urdering of the OWh operators in $\mathbf{T}$.

Wi: will cuow prove that the following letrimas tuold.

LEMMA 2 The untite $D i s p(\phi)=D i s p\left(\phi_{0}\right)+\sum_{j=1}^{r} w_{0, j} D i s p\left(\phi_{j}\right)$ is marimum if and onty af the orderitg is , . . b, nertfes

$$
\left.i \leq j \text { if and onfy of Disp( } \dot{\phi}_{\pi(i)}\right) \geq \operatorname{Disp}\left(\phi_{\mathbf{x}(j)}\right)
$$

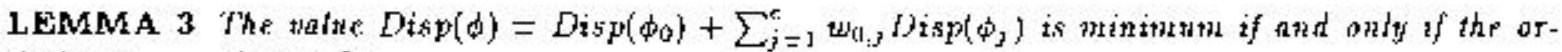
Atring $\phi_{1}, \ldots, \phi_{2}$ verifies

$$
\left.i \leq j \text { if ard onty of } \operatorname{Disp}\left(\phi_{\times i}\right)\right) \leq \operatorname{sisp}\left(\phi_{\square}(j)\right.
$$

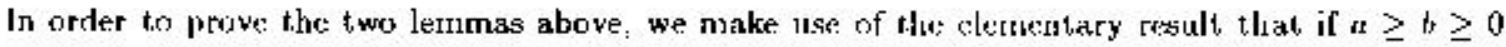
and $c>d \geq 0$ then $a c+b d \geq a d+b r$.

(L1) Let us then prove Lemma 2

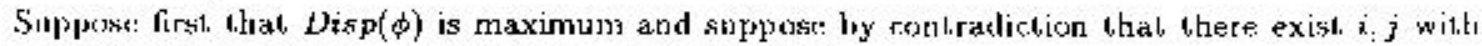
$i<j$ such that $\operatorname{fisp}\left(\phi_{\pi(i)}\right)<\operatorname{Disp}\left(\phi_{*(j)}\right)$. Then since

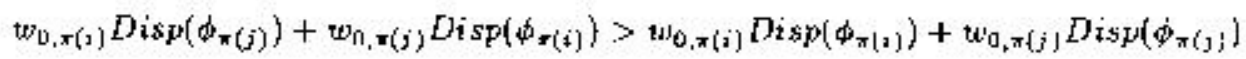

by swilching $\phi_{i}$ and $\phi_{j}$ we would obtain an ordering which would cause the dispersion of the: hierarchical aggregetion do increase, contradicting the initial hypothesys. 
Gonversely, suppose that the ordering $\phi_{1} \ldots \phi_{-}$verifies the condition of the J,erntria. Let $\phi_{1}^{\prime}, \ldots, \phi_{r}^{\prime}$ be an ordering which maximizes $U i s p(\phi)$. From what has been proven alowe, llis ordering verities the condition of the Letuma as well.

Let. us prove that.

$$
\sum_{j=1}^{c} w_{\phi, j} D i s p\left(\phi_{j}\right)=\sum_{j=1}^{r} w_{\phi_{j, j}} \operatorname{Disp}\left(\phi_{\mathrm{J}}^{t}\right) .
$$

If $\phi_{\pi(1)} \neq \phi_{\pi(1)}^{\prime}$ in viow of the condilion of the Lemma it must be

$$
\operatorname{Disp}\left(\phi_{\pi(1)}\right)-\operatorname{Disp}\left(\phi_{x(1,}^{\prime}\right)
$$

'Thus. we are left. to prows that

$$
\sum_{j \neq>(1)} w_{n, j} D_{i s j p}\left(\phi_{j}\right)=\sum_{j \neq=\{1 ;} w_{0, j} \operatorname{Disp}\left(\phi_{j}^{j}\right)
$$

which can be shown easily to hold, by applying a recursive argument.

(Ir2) f.emma 3 can be proven analogously.

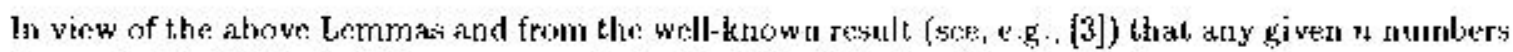
can les sorted in $\mathcal{O}(n \log s)$ time, we can claim that the following theorem is true.

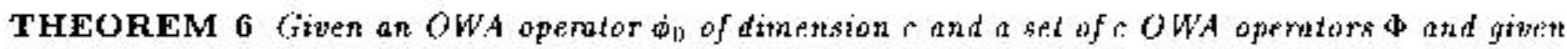

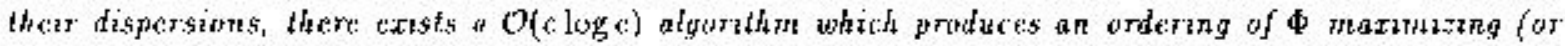
manintarng) the daspersion of the hatrarchatal aggragation.

\subsection{Orness}

The problem of maximizing or minirruzing the oruszs of the tijeraretical aggregalion at a first sight, appears to be quite more difficult from a computational point of view and its (polynomial) solution definitely more subtle. However we can scte that we tan chily reduce such a problem lo the classical combinatorial assigrament probtem for which there exists a $\mathcal{O}\left(c^{3}\right)$ algorithm.

Let. Is go back to the algebraic expression for computing th: oruess of the hierarchical aggregalicu ones an ordering $\phi_{1}, \ldots$, $\phi_{e}$ of the $O W A$ ojeraturs in $\Phi$ has been fixed:

$$
\operatorname{aracss}(\phi)=\sum_{i=1}^{c} \frac{\left(h_{i}-1\right) \operatorname{arntess}\left(\phi_{i}\right)+r-\sum_{j=1}^{\mathrm{t}} h_{j}}{\mathrm{r}-1} w_{n, i}
$$

Thus

$$
\operatorname{arness}(\phi)=\sum_{i=1}^{c} \frac{\left(h_{i}-1\right) \operatorname{orness}\left(\phi_{2}\right) \mu_{0.1}+n-\sum_{j=i}^{c} w_{0, j} h_{i}}{r_{t}-1} .
$$

We can therefore conclude that the contributing to the orness of $\phi$ of an OWA operator $\bar{\phi} \in \Phi$ with 
dimension $h$ will be

$$
\begin{aligned}
& \delta(\bar{\phi}, 1)=\frac{(h-1) \text { or noss }(\bar{\phi}) n_{0, a}+n \cdots h}{\pi-1} \quad \text { if } \bar{\phi} \text { is the first } \\
& \delta(\bar{\phi}, 2)=\frac{(h-1) \operatorname{arn} n=\pi(\phi) w_{0,2}+n-\left(1-w_{0}, 1\right)}{n-1} \quad \text { if } \phi \text { is the socond } \\
& \delta(\bar{\phi}, i)=\frac{(h-1) \operatorname{armess}(\bar{\phi}) \omega_{0,1}+n-\sum_{,=1}^{r} w_{0, \gamma^{h}}}{n-1} \quad \text { if } \phi \text { is the } i-t, h \\
& \vdots
\end{aligned}
$$

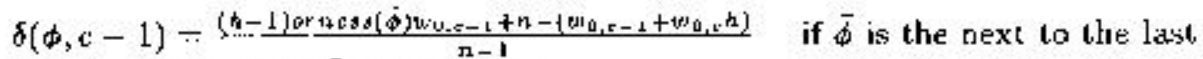

$$
\begin{aligned}
& \delta(\bar{b}, c)=\frac{\left\{h-1 \text { torness }(\bar{\phi}) w_{d, c}+n \cdots w_{U, c} c^{b}\right.}{n-1} \quad \text { if } \bar{\phi} \text { is the last }
\end{aligned}
$$

Summing up we can say that:

- denoted with $\phi_{1}, \phi_{2}, \ldots \varphi_{c}$ the OWh ojerators in $\phi$, and

- clenoted for simplicity with $\delta_{i j}$ the contribution to the orness of $\phi$ of the operator ob atec it. is chosen as the $j-1, h_{1}$ in thr: hierarehical agyegation, then

- thi: problem of maximizing [resp. minimizing the orness of the hierarchical aggregation is equiv aleat wo the problem of fincling a prermutation $\pi$ of the rows of the matrix

$$
M=\left(\begin{array}{llll}
\delta_{11} & \delta_{12} & \ldots & \delta_{15} \\
\delta_{21} & \delta_{22} & \ldots & \delta_{2 c} \\
\vdots & \vdots & \ddots & \vdots \\
\delta_{c 1} & \delta_{r 2} & \ldots & \delta_{r \varepsilon}
\end{array}\right)
$$

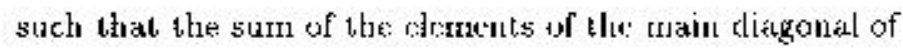

$$
M_{\pi}=\left(\begin{array}{llll}
\delta_{\pi\{t 11} & \delta_{\pi(1) 2} & \ldots & \delta_{\pi(1) r} \\
\delta_{r(2) 1} & \delta_{\pi(2) 2} & \ldots & \delta_{\pi(2) c} \\
\vdots & \vdots & \ddots & \vdots \\
\delta_{r(r) 1} & \delta_{\pi(r) 2} & \ldots & \delta_{\pi(r) r}
\end{array}\right)
$$

is rraximum [resp. minimum], i.c. such that,

$$
\sum_{i=1}^{c} \delta_{x(i) i}
$$

is maximum [resp. minimum].

The above is the classical assignment problem (also known as the biparite weaghted matchitug prob(ert) (ske: [21], chaptet 11) and can be solved by the so-called hungarian method (see [16]) in time $O\left(c^{3}\right)$. More recently in [22] it has ben prover that by usidg special data structurcs it is possibie to improve. the above bound to $O\left(c^{2} \log c\right)$.

\subsection{Some particular cases}

$O(c \log c)$ algorithms can iustead be given for the most gignificative cascs in practice. Since each onc of the given c OWA opmators represents partial information to be aggregated into only ore inclex, it is common to define them is such a way that either 
- they contair the same amount of information. In this case, all OWA operators in $\mathbf{\phi}$ will have the same dirmension $h$ sucht that, $n=h$ e; or

- they treat tleeir inputs with the same (legree of optiyrism (pessimism). In this case, all OWA operators will have the same degree of orroms.

l.et us consider the above two cases in more retcicils.

(case 1) In case all OWA oper ators in $\Phi$ have the same dimension $h=r / c_{1}$ we have to find an ordering \$1: ..., so such that

$$
\operatorname{arness}(\phi)=\sum_{i=1}^{n} \frac{(h-1) \operatorname{crrtcss}\left(\phi_{i}\right)+n-\sum_{i=1}^{i} h}{n-1} w_{0, i}
$$

is maximum. Therefore:

$$
\text { orretsis }(\dot{\phi})=\frac{(h-1)}{n-1} \sum_{1=1}^{c} \operatorname{orness}\left(\phi_{i}\right) w_{0, i}+\frac{\sum_{i=1}^{c}(r \cdot i) h}{n-1} w_{0, i}
$$

It follows that the sought ordering can be thltained as in Lemma 2, i.e. by producing any ordering which yerifies

$$
i \leq j \text { if and only if orness }\left(\phi_{r(i)}\right) \leq \text { orness } s\left(\phi_{\pi \mid j}\right)
$$

Anclogously. if we wast lo minimize the orness of the hierarchical aggregation we act as in Lemma 3.

(case 2) in caste all OWA oprcators in $\Phi$ have the same orness $r$, we have

$$
\operatorname{aress}(\phi)=\frac{1}{n-1} \sum_{i=1}^{c}\left(r h_{i}+\sum_{j=a+1}^{c} h_{j}\right) w_{0,2}-i_{n-i}^{r}
$$

As a conserunchel, any urdering which sorts the elements of $\Phi$ in increasing [resp. decreasing] order wilb respect to therr dimensions maxirrizess [resp. minimizes] the ornoss.

\section{$7 \quad$ Final Comments}

It this praper, we surveyed on some research work that has bech thut to oltain a full charaterization of rational aggregation operators aud lierarchies of thern. In particular we focused on the propagation of key ethical condilions, rationality and stability properties of cover-based hierarclies and ordercd hierarchies. In this last tasso, we have analyzect Yager's OWA operators and seen that the property of being an OWA uperator propagates under ordered hierarchical aggregatious. As by product. we olsserved interesting theoretical and computatational results on the propagation of OWA operators significant measures surh is orness and dispersion,

We conclude by again pointing out the pratitical importance of such hierarchical aggregation rulcs. Preference intensity of large groups of people are in common life usually aggregated by means of hierarchical procedurs. The fact tbal standard ethical conditions as well as non absolute irrationality, together with stability, propagale under general conditions legitimize hierarchical aggregations from buth theoretical and applicative point of virw.

Acknowledgment: This research has been partially supported by Lireccion General de Inveytigación Científica y Técnica (Spain). 


\section{References}

[1] K.J. Arrow. Social Chotre and Individuat Values. John Wilcy \& Sons, Inc., New York, 1964.

[2] W. Cholewa. Aggreggtion of fuzzy opinions: an axiomatic approach. Fuzzy ssts and systerns, $17: 249258,1985$

[3] T H. Cormen, C.E. Leiserson and R. R. Rivest. Inirodtrtion to Algerzthms. MIT Press, Cambridge, HA. 1990.

[4] Y c 'utello and J. Montero. A model for amalganation in group decision thaking. In NAFIPS 1992. Puerto Vallarta: Mexico. [992. F'roceedings of thre North Arnerican F'uzzy Information F'ro. cessing Society International Conference on Fuzzy set theory and applications. NASA conference. publications 10112 , Vol. I, p. 215-223.

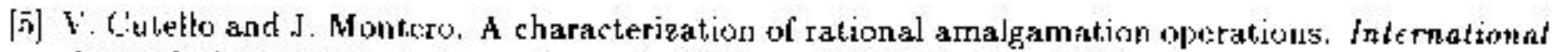
faterstat of Approsimate Reasoning, vol. 8 (4): pp. 325-344, June 1993.

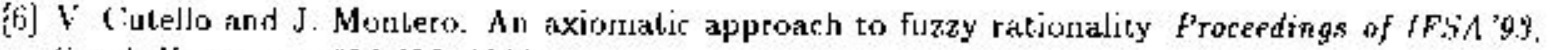
Sirust. Korea, pg: 634-636. 1993.

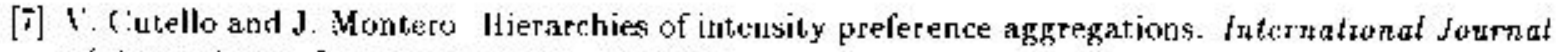
of Approrimate Reasoneng, 10:123-133, 1994.

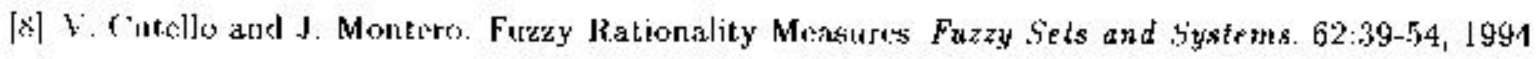

[S] V Cutello and $\mathbf{J}$. Montero. Computational problems of the hierarchical aggregation of OWA

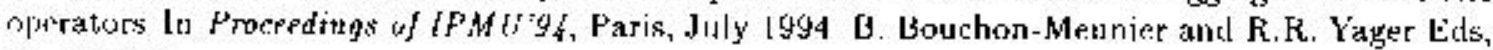
p.p. 407.411

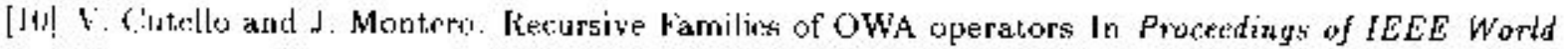
Congress on Computatronal Intelligrnce, FUZZ-1EEE 94, Orlando, Florida, June 1994. P. Bonjssone Ed, IFEE Presis, pp. 2046-2049.

[II] F. Ciutello atud J. Montero. Hierarchies of aggregation opetators. International fournal of Intettigrext Systems, 9:1025-1045, 1994.

[12! 4 Cutello and J. Montero. Hierarchical aggregation of OWA operators: hasic measurus attel relatecl computational problens. Submitted

[13] D. Dubois and J.L. Koning. Social choice axioms for fuxzy set, aggregation. Fuzzy sets and systems. $43: 257-274,1991$.

[14] L.W. Fung and K.S. Fu. An axiomatic approach to rational decision making in a fuzzy euvironment. Ir L.A. Zadeh, K.S. Fu, K. Tanaket, atud M. Shimura, editors, Fuzzy sets and thrir applications to Cognitive and dectsion processes, pages 227-256. Academic. Press, 1975.

[1.3] (i.]. Klir and T.A. Folger. Fuzzy sets, ancertainty and information. Prentice Hall, Enylewowd Clifts: NJ, 1988.

[16] H.W Kutn. The Hungarian Metbod for the assignirnent Problem. Navul Rescarch Logistics Quarterly, 2:83-97, 1955. 
[17] J. Montero. A tute on Fing-Fu's theorem. Fyzzy sets and sysiems, 17:259-269, 1985.

[18] J. Montero. Arrow's thoorem under fuzzy rationalicy. Behavioml Scituce, pages 267-273, 1987.

[19] J. Montero. Social welfare functions in a fuzzy environment. Kybenctes, 16:24]-245, 1987.

[20] S. Ovchinnikov. Means and social welfare function in fuzzy binary relation spaces. In J. Kixprzyk and M. Fedrizzi, editors, Mndiperson decision makng using fozzy sefs and possubrlity theory: pages 143-154. Kluwer, 1990.

[21] C.L. Papadimitriou and K. Steiglitz. Combinatorind Oplimization. Algorithms and Complesty. Prentice Hall, Englewood Clifs: NJ, 1982.

[22) M.L. Fredman and R.E. Tarjan. Fibonaci beaps and their uses in improved network optimization algorithms. Jowrnal of A.C.M., 34(3):596-615, 1987

[23] R.R. Yager. Connestivis and quantifiers in fuzzy sets. Futzzy sets and Sustems, 40:39-75, 199i

[24] R.Fl. Yager. On ordered weighted averaging agrregation operators in multi-criteria derision making. IEEE transactions on systems, man ard cybernetics, 18:183 190, $19 \times 4$.

[25] R.R. Yager. Farrilies of OWh opwrators. fuzzy sets and systems, 59:125-148, 1993. 